\title{
Myoclonic Jerk
}

National Cancer Institute

\section{Source}

National Cancer Institute. Myoclonic Jerk. NCI Thesaurus. Code C34832.

A sudden, involuntary contraction of a muscle or group of muscles; these movements

may develop as a symptom of a number of neurological diseases, including epilepsy,

Parkinson's disease, Alzheimer's disease, or Creutzfeldt-Jacob disease. 